Article

\title{
Pimarane Diterpenoids from the Seeds of Caesalpinia minax as PTP1B Inhibitors and Insulin Sensitizers
}

\author{
Yunshao Xu ${ }^{1,+}$, Zheling Feng ${ }^{1,+}$, Tian Zhang ${ }^{1}$, Peng Lv ${ }^{1}$, Jun Cao ${ }^{1}$, Dan $\mathrm{Li}^{2}{ }^{2}$, Cheng Peng ${ }^{2}$ and \\ Ligen Lin $1,2, *$ (D) \\ 1 State Key Laboratory of Quality Research in Chinese Medicine, Institute of Chinese Medical Sciences, \\ University of Macau, Macao SAR 999078, China; mb75820@um.edu.mo (Y.X.); yb77508@um.edu.mo (Z.F.); \\ yb67520@um.edu.mo (T.Z.); yb87503@um.edu.mo (P.L.); yb97509@um.edu.mo (J.C.) \\ 2 State Key Laboratory of Southwestern Characteristic Chinese Medicine Resources, School of Pharmacy, \\ Chengdu University of Traditional Chinese Medicine, Chengdu 610075, China; lidan@cdutcm.edu.cn (D.L.); \\ pengchengchengdu@126.com (C.P.) \\ * Correspondence: ligenl@um.edu.mo; Tel.: +853-8822-8041 \\ + These authors contributed equally to this work.
}

Received: 15 September 2020; Accepted: 12 October 2020; Published: 13 October 2020

\begin{abstract}
Protein-tyrosine phosphatase 1B (PTP1B) has been considered as a promising target for treating insulin resistance. In searching for naturally occurring PTB1B antagonists, two new pimarane diterpenoids, named $2 \alpha$-hydroxy-7-oxo-pimara-8(9),15-diene (1) and 19-hydroxy-2 $\alpha$-acetoxy-7-oxopimara-8(9),15-diene (2), were isolated from the seeds of Caesalpinia minax. Their structures were determined by extensive analysis of NMR and HR-ESIMS data, and their absolute configurations were determined by electronic circular dichroism (ECD) spectra. Compound $\mathbf{1}$ was disclosed as a competitive inhibitor of PTP1B with an $\mathrm{IC}_{50}$ (the half-maximal inhibitory concentration) value of $19.44 \pm 2.39 \mu \mathrm{M}$ and a Ki (inhibition constant) value of $13.69 \pm 2.72 \mu \mathrm{M}$. Moreover, compound 1 dose-dependently promoted insulin-stimulated glucose uptake in $\mathrm{C} 2 \mathrm{C} 12$ myotubes through activating insulin signaling pathway. Compound $\mathbf{1}$ might be further developed as an insulin sensitizer.
\end{abstract}

Keywords: pimarane diterpenoids; Caesalpinia minax; PTP1B; glucose uptake; C2C12 myotubes

\section{Introduction}

Protein tyrosine phosphatases (PTP) are specific, tightly regulated, and critical modulators of cellular signal initiation, transduction and termination [1]. PTP1B dephosphorylates tyrosine residues in insulin receptor (IR) and IR substrate 1 (IRS1), reducing insulin sensitivity and shutting down insulin signaling [1,2]. Additionally, PTP1B dephosphorylates leptin receptor and Janus kinase 2, functioning as a negative regulator of leptin signaling [1]. Thus, PTP1B inhibitors enhance the sensitivities of insulin and leptin signaling and have favorable curing effect for diabetes and obesity [1,2]. Up to now, only two small-molecular PTP1B antagonists, ertiprotafib [3] and trodusquemine [4], have reached clinical trials, but both were failed. Hence, it is urgent to identify potent and selective small-molecular PTP1B inhibitors. Natural products, including fatty acids, phenolics, terpenoids, steroids and alkaloids, provide a great amount of PTP1B inhibitors with structural diversity $[5,6]$.

The seeds of Caesalpinia minax Hance (Fabaceae), called "ku-shi-lian" in China, have been traditionally used for healing dysentery, rheumatism and the common cold [7]. Lots of phytochemical investigations have identified more than 150 cassane diterpenoids from the titled species [8,9]. Although cassane diterpenoids are considered as the rearranged products of pimarane precursors through a methyl migration from C-13 to C-14, pimarane diterpenoids were seldom reported from the genus Caesalpinia. Till now, only two pimarane diterpenoids, pulcherrin $\mathrm{R}$ and tomocinol $\mathrm{C}$, were isolated from Caesalpinia 
species $[10,11]$. In a search for PTP1B inhibitors, two new pimarane diterpenoids were identified from the seeds of $C$. minax Hance. Herein, the isolation and structure elucidation of new pimarane diterpenoids, as well as their PTP1B inhibitory and insulin-sensitizing activities, are reported.

\section{Results and Discussions}

\subsection{Structure Elucidation}

Compound 1, a white amorphous powder, possessed a molecular formula of $\mathrm{C}_{20} \mathrm{H}_{30} \mathrm{O}_{2}$ based on the protonated ion peak at $m / z 303.2326$ (calcd. for $\mathrm{C}_{20} \mathrm{H}_{31} \mathrm{O}_{2}, 303.2324$ ) in the HRESIMS (high resolution electrospray ionization mass spectrometry), indicating six degrees of unsaturation. The broad infrared (IR) absorption at $3452 \mathrm{~cm}^{-1}$ suggested the presence of hydroxy group in the structure of 1 . The ultraviolet (UV) absorption maximum at $245 \mathrm{~nm}$ together with the IR absorption at $1742 \mathrm{~cm}^{-1}$ indicated the existence of an $\alpha, \beta$-unsaturated ketone moiety [12]. The ${ }^{1} \mathrm{H}-\mathrm{NMR}$ (proton nuclear magnetic resonance) spectrum of $\mathbf{1}$ (Table 1 ) displayed resonances for four methyls $\left[\delta_{\mathrm{H}} 1.10(3 \mathrm{H}, \mathrm{s})\right.$, $0.97(3 \mathrm{H}, \mathrm{s}), 0.96(3 \mathrm{H}, \mathrm{s})$ and $0.95(3 \mathrm{H}, \mathrm{s})]$, one oxygenated methine $\left[\delta_{\mathrm{H}} 3.99(1 \mathrm{H}, \mathrm{tt}, J=11.5,4.1 \mathrm{~Hz})\right]$, and three olefinic protons ascribed to a vinyl group $\left[\delta_{\mathrm{H}} 5.74(1 \mathrm{H}, \mathrm{dd}, J=17.4,10.8 \mathrm{~Hz})\right.$ and $4.90(2 \mathrm{H}$, $\mathrm{m})$ ]. The ${ }^{13} \mathrm{C}-\mathrm{NMR}$ (carbon-13 nuclear magnetic resonance) and DEPT-135 (distortionless enhancement by polarization transfer-135) spectra of $\mathbf{1}$ (Table 1) exhibited 20 resonances attributed to one ketone carbonyl carbon $\left(\delta_{C} 199.7\right)$, four olefinic carbons $\left(\delta_{C} 164.6,147.2,129.1\right.$ and 111.0), three quaternary carbons $\left(\delta_{C} 41.2,34.8\right.$ and 34.3$)$, two methine carbons $\left(\delta_{C} 65.1\right.$ and 49.4$)$, six methylene carbons $\left(\delta_{C}\right.$ $50.5,45.0,35.3,33.6,33.1$ and 22.9$)$ and four methyl carbons $\left(\delta_{C} 32.6,24.9,22.4\right.$ and 19.5). The above evidence revealed that 1 possesses a pimarane diterpenoid framework, and its ${ }^{1} \mathrm{H}$ - and ${ }^{13} \mathrm{C}-\mathrm{NMR}$ data quite resembled those of isopimara-8,15-dien-7-one [12,13]. The main difference was a methylene group in isopimara-8,15-dien-7-one was replaced by an oxygenated methine $\left(\delta_{\mathrm{H}} 3.99 / \delta_{\mathrm{C}} 65.1\right)$ in 1 . The HMBC (heteronuclear multiple bond correlation) cross peaks between the oxygenated methine proton $\left(\delta_{\mathrm{H}} 3.99\right)$ and $\mathrm{C}-1\left(\delta_{\mathrm{C}} 45.0\right), \mathrm{C}-3\left(\delta_{\mathrm{C}} 50.5\right), \mathrm{C}-4\left(\delta_{\mathrm{C}} 34.8\right)$ and $\mathrm{C}-10\left(\delta_{\mathrm{C}} 41.2\right)$ assigned it as $\mathrm{C}-2$, which was further supported by the coupling constant of $\mathrm{H}-2$. Thus, the planar structure of compound $\mathbf{1}$ was established. The relative configuration of $\mathbf{1}$ was inferred by ROESY (rotating frame Overhause effect spectroscopy) experiment, indicating the same as pimarane diterpenoids. The NOE (nuclear Overhause effect) correlations between $\mathrm{H}-2$ and $\mathrm{H}_{3}-18$ and $\mathrm{H}_{3}-20$ indicated that the hydroxy group on $\mathrm{C}-2$ was $\alpha$-oriented. To identify the absolute configuration of $\mathbf{1}$, an electronic circular dichroism (ECD) spectrum was acquired and analyzed. Compound 1 exhibited negative and positive Cotton effects at 250.5 and $322.0 \mathrm{~nm}$, respectively, matching the spectrum for the normal pimarane quite well [14]. Thus, the absolute configuration of $\mathbf{1}$ was determined as $2 S, 5 S, 10 S$, and $13 S$. Accordingly, the structure of 1 was established, and it was named $2 \alpha$-hydroxy-7-oxo-pimara-8(9),15-diene (Figure 1).
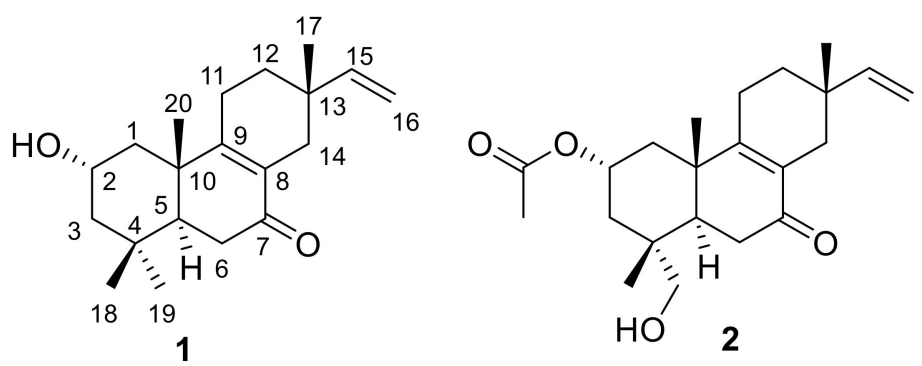

Figure 1. Chemical structures of compounds $\mathbf{1}$ and $\mathbf{2}$.

Compound 2 was obtained as a white amorphous powder. Its molecular formula was assigned as $\mathrm{C}_{22} \mathrm{H}_{32} \mathrm{O}_{4}$ according to the protonated ion peak at $m / z 361.2374[\mathrm{M}+\mathrm{H}]{ }^{+}$(calcd. for $\mathrm{C}_{22} \mathrm{H}_{32} \mathrm{O}_{4}$, 361.2379) in its HRESIMS. The presences of hydroxy and ketone groups in the structure of 2 were inferred by the broad IR absorption at $3442 \mathrm{~cm}^{-1}$ and the sharp IR absorption at $1729 \mathrm{~cm}^{-1}$, respectively. 
The ${ }^{1} \mathrm{H}-\mathrm{NMR}$ spectrum exhibited signals for three methyl group $\left[\delta_{\mathrm{H}} 1.18(3 \mathrm{H}, \mathrm{s}), 0.95(3 \mathrm{H}, \mathrm{s})\right.$, and 0.94 $(3 \mathrm{H}, \mathrm{s})]$, one acetoxy group $[2.05(3 \mathrm{H}, \mathrm{s})]$, one oxygenated methine $\left[\delta_{\mathrm{H}} 5.16(1 \mathrm{H}, \mathrm{tt}, J=11.7,4.3 \mathrm{~Hz})\right]$, one oxygenated methylene $\left[\delta_{\mathrm{H}} 3.43(1 \mathrm{H}, \mathrm{d}, J=10.9 \mathrm{~Hz})\right.$ and $\left.3.15(1 \mathrm{H}, \mathrm{d}, J=10.9 \mathrm{~Hz})\right]$, and three olefinic protons ascribed to a vinyl group $\left[\delta_{\mathrm{H}} 5.73(1 \mathrm{H}, \mathrm{dd}, J=17.4,10.8 \mathrm{~Hz})\right.$ and $\left.4.90(2 \mathrm{H}, \mathrm{m})\right]($ Table 1$)$. The ${ }^{13} \mathrm{C}-\mathrm{NMR}$ spectrum of 2 exhibited 22 carbon resonances (Table 1 ). The ${ }^{1} \mathrm{H}$ - and ${ }^{13} \mathrm{C}-\mathrm{NMR}$ data for compound 2 were quite similar to those of compound 1 . After careful analysis of 2D NMR, the hydroxy group at C-2 in $\mathbf{1}$ was replaced by an acetoxy group in 2 . In the HMBC spectrum, the correlations from the oxygenated methylene protons to $C-2\left(\delta_{C} 68.4\right), C-3\left(\delta_{C} 40.0\right), C-4\left(\delta_{C} 39.0\right)$ and $C-5\left(\delta_{C} 42.3\right)$, indicated that one of the methyl groups on C-4 was replaced by a hydroxymethyl group in 2 . Next, a ROSEY experiment was carried out to elucidate the relative configuration of $\mathbf{2}$. The NOE correlations between $\mathrm{H}-2$ and $\mathrm{H}_{3}-18$ and $\mathrm{H}_{3}-20$, as well as between $\mathrm{H}-5$ and $\mathrm{H}_{2}-19$, indicated that the hydroxy group was attached to C-19 and the acetoxy group on C-2 was $\alpha$-oriented. The ECD spectrum indicated the absolute configuration of $\mathbf{2}$ to be the same as that of $\mathbf{1}$, assigning as $2 S, 3 S, 5 S, 10 S$, and 13S. Therefore, the structure of 2 was established, named 19-hydroxy-2 $\alpha$-acetoxy-7-oxo-pimara-8(9),15-diene (Figure 1).

Table 1. ${ }^{1} \mathrm{H}$ - and ${ }^{13} \mathrm{C}-\mathrm{NMR}$ Spectroscopic Data $\left(\mathrm{CDCl}_{3}\right)$ for Compounds $\mathbf{1}$ and $2\left(\delta_{\mathrm{H}}\right.$ in ppm, J in $\left.\mathrm{Hz}\right)$.

\begin{tabular}{|c|c|c|c|c|}
\hline \multirow{2}{*}{ Position } & \multicolumn{2}{|l|}{1} & \multicolumn{2}{|l|}{2} \\
\hline & $\delta_{\mathrm{H}}(J \text { in } \mathrm{Hz})^{a}$ & $\delta_{\mathrm{C}}^{b}$ & $\delta_{\mathrm{H}}(J$ in $\mathrm{Hz})$ & $\delta_{\mathrm{C}}$ \\
\hline & $\alpha 2.21, \mathrm{~m}$ & & $\alpha 2.21, \mathrm{~m}$ & \\
\hline 1 & $\beta 1.21, \mathrm{~m}$ & 45.0 & $\beta 1.32, \mathrm{t}(11.7)$ & 40.8 \\
\hline \multirow[t]{2}{*}{2} & $3.99, \mathrm{tt}(11.5,4.1)$ & 65.1 & $5.16, \mathrm{tt}(11.7,4.3)$ & 68.4 \\
\hline & $\alpha 1.85, \mathrm{ddd}(12.5,4.1,2.2)$ & & $\alpha 1.69, \mathrm{~m}$ & \\
\hline 3 & $\beta 1.20, \mathrm{~m}$ & 50.5 & $\beta 1.63, \mathrm{~m}$ & 40.0 \\
\hline 4 & - & 34.8 & - & 39.0 \\
\hline \multirow[t]{2}{*}{5} & $1.71, \mathrm{~m}$ & 49.4 & $2.13, \mathrm{~m}$ & 42.3 \\
\hline & $\alpha 2.53, \mathrm{~m}$ & & $\alpha 2.45, \mathrm{dd}(17.6,4.0)$ & \\
\hline 6 & $\beta 2.36, \mathrm{~m}$ & 35.3 & $\beta 2.35, \mathrm{~m}$ & 34.9 \\
\hline 7 & - & 199.7 & - & 199.1 \\
\hline 8 & - & 129.1 & - & 129.3 \\
\hline 9 & - & 164.6 & - & 164.3 \\
\hline \multirow[t]{2}{*}{10} & - & 41.2 & - & 40.8 \\
\hline & $\alpha 2.31, \mathrm{~m}$ & & $\alpha 2.25, \mathrm{~m}$ & \\
\hline 11 & $\beta 2.25, \mathrm{~m}$ & 22.9 & $\beta 2.21, \mathrm{~m}$ & 22.9 \\
\hline 12 & $1.44-1.52, \mathrm{~m}(2 \mathrm{H})$ & 33.1 & $1.45-1.49, \mathrm{~m}(2 \mathrm{H})$ & 33.5 \\
\hline \multirow[t]{2}{*}{13} & - & 33.6 & - & 34.3 \\
\hline & $\alpha 2.34, \mathrm{~m}$ & & $\alpha 2.32, \mathrm{~m}$ & \\
\hline 14 & $\beta 1.99, \mathrm{~m}$ & 33.6 & $\beta 1.97, \mathrm{~m}$ & 33.0 \\
\hline 15 & $5.74, \mathrm{dd}(17.4,10.8)$ & 147.2 & $5.73, \mathrm{dd}(17.4,10.8)$ & 147.1 \\
\hline 16 & $4.90, \mathrm{~m}(2 \mathrm{H})$ & 111.0 & $4.90, \mathrm{~m}(2 \mathrm{H})$ & 111.0 \\
\hline 17 & $0.95, \mathrm{~s}$ & 24.9 & $0.95, \mathrm{~s}$ & 24.9 \\
\hline 18 & $0.96, \mathrm{~s}$ & 32.6 & $3.43,3.15, \mathrm{~d}(10.9)$ & 70.1 \\
\hline 19 & $0.97, \mathrm{~s}$ & 22.4 & $0.94, \mathrm{~s}$ & 18.2 \\
\hline 20 & $1.10, \mathrm{~s}$ & 19.5 & $1.18, \mathrm{~s}$ & 19.8 \\
\hline $2-\mathrm{OCOCH}_{3}$ & - & - & - & 170.7 \\
\hline $2-\mathrm{OC} \mathrm{OCH}_{3}$ & - & - & $2.05, \mathrm{~s}$ & 21.6 \\
\hline
\end{tabular}

\subsection{PTP1B Inhibitory Activity}

Compounds 1 and 2 were assayed for their PTP1B inhibitory activity using 4-nitrophenyl phosphate disodium salt (pNPP) as the dephosphorylating substrate. pNPP is dephosphorylated to yield the product $p$-nitrophenol, which could be monitored at an absorbance of $405 \mathrm{~nm}$ and the slope of the initial rate of the kinetic curve in each well was applied to determine the activity of PTP1B [15]. Oleanolic acid, a well-documented PTP1B inhibitor, was used as a positive control [15]. Compounds 1 and 2, as well as oleanolic acid, were dissolved in dimethyl sulfoxide (DMSO) to make $10 \mathrm{mM}$ stock 
solutions, which were further diluted in reaction buffer or cell culture medium to the corresponding concentrations. Under the concentration of $200 \mu \mathrm{M}$, compound $\mathbf{1}$ and oleanolic acid reduced PTP1B activity at the rate of $76.6 \%$ and $93.4 \%$, respectively, but not compound $2(6.5 \%)$. Thus, compound 1 was selected for further studies. Compound 1 dose-dependently inhibited PTP1B activity with an $\mathrm{IC}_{50}$ (the half-maximal inhibitory concentration) value of $19.44 \pm 2.39 \mu \mathrm{M}$ (Figure $2 \mathrm{~A}$ ), which was comparable to that of oleanolic acid $\left(\mathrm{IC}_{50}=3.98 \pm 0.98 \mu \mathrm{M}\right)$ (Figure $\left.2 \mathrm{~B}\right)$.

A
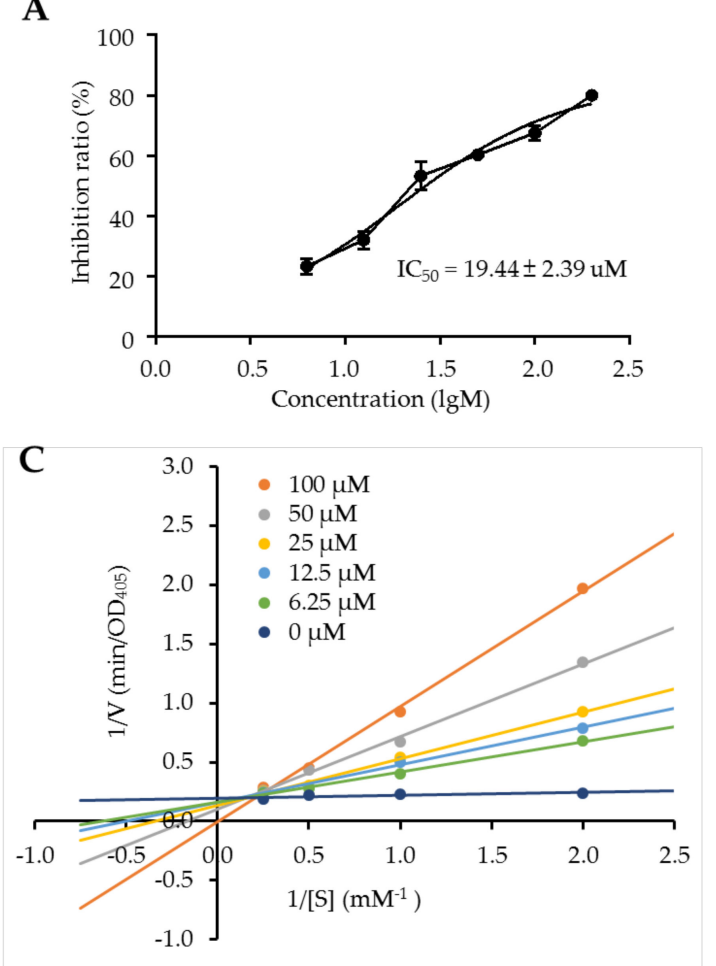

\section{B}
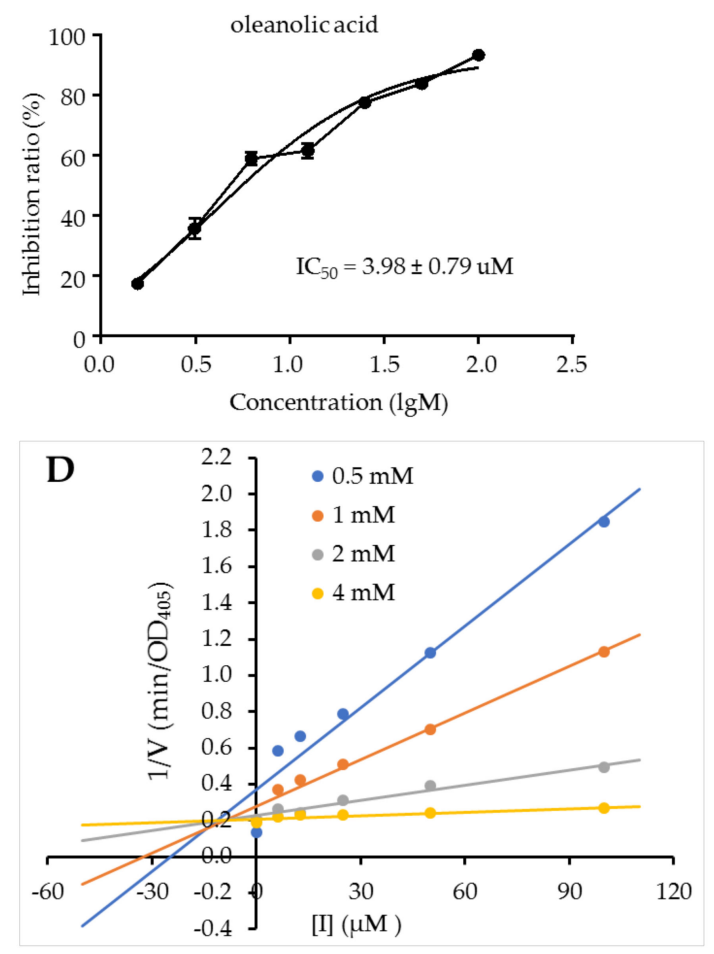

Figure 2. Protein-tyrosine phosphatase 1B (PTP1B) inhibitory activity and kinetic analysis for compound 1. Concentration-PTP1B inhibition ratio curves of compound $\mathbf{1}(\mathbf{A})$ and the positive control oleanolic acid (B). (C) Lineweaver-Burk plot for the inhibition of PTP1B by compound 1. (D) Dixon plot for the inhibition of the PTP1B by compound 1. Data are expressed as mean \pm SD, $n=4$.

To further investigate the PTP1B enzyme inhibition type and inhibition constant (Ki) of compound 1, Lineweaver-Burk and Dixon plots were analyzed with different concentrations of compound $\mathbf{1}(0,6.25$, $12.5,25,50$ and $100 \mu \mathrm{M})$ and pNPP $(0.5,1,2$ and $4 \mathrm{mM})$, respectively $[16,17]$. Competitive inhibitors have the same $y$-intercept but different slopes and $x$-intercepts; non-competitive inhibition produces plots with the same $x$-intercept but different slopes and y-intercepts; and uncompetitive inhibition causes different intercepts on both the $y$ - and x-axes. The Lineweaver-Burk (Figure 2C) and Dixon plots (Figure 2D) of compound $\mathbf{1}$ intersected at the $y$-side, revealing a competitive inhibition mode. Compound 1 might directly interact with the active binding sites of the PTP1B enzyme. The Dixon plot has been widely recruited to determine the Ki for an enzyme-inhibitor complex [17]. Herein, the Ki value of $\mathbf{1}$ was calculated to be $13.69 \pm 2.72 \mu \mathrm{M}$, indicating compound $\mathbf{1}$ was a potent PTP1B inhibitor.

\subsection{Glucose Uptake Stimulatory Property on C2C12 Myotubes}

Mouse $\mathrm{C} 2 \mathrm{C} 12$ myotubes have been widely used as an in vitro model to mimic skeletal muscle $[18,19]$. The fully differentiated $\mathrm{C} 2 \mathrm{C} 12$ myotubes uptake glucose from culture medium upon insulin stimulation, which has been widely used to screen and validate insulin sensitizer [18]. Herein, the glucose uptake stimulatory property of compound 1 was evaluated on $\mathrm{C} 2 \mathrm{C} 12$ myotubes. 5-Aminoimidazole-4-carboxamide ribonucleotide (AICAR, $20 \mu \mathrm{M}$ ), an activator of AMP-activated protein kinase (AMPK), was used 
as a positive control. Firstly, the non-cytotoxic concentrations of compound $1(3.125,6.25,12.5,25$, 50 and $100 \mu \mathrm{M})$ on C2C12 myotubes were evaluated by the MTT [3-(4,5-dimethylthiazol-2-yl)-2,5diphenyltetrazolium bromide] assay, to determine the maximum safe dosage. Compound 1 didn't show obvious cytotoxicity up to $50 \mu \mathrm{M}$ when treated for $24 \mathrm{~h}$ (Figure 3A). Next, insulin-stimulated glucose uptake on $\mathrm{C} 2 \mathrm{C} 12$ myotubes was evaluated to determine the insulin-sensitizing effect of compound $\mathbf{1}(10,20$ and $40 \mu \mathrm{M})$. Compound $\mathbf{1}$ didn't obviously affect glucose uptake without insulin stimulation (Figure 3B). As expected, insulin dramatically enhanced glucose uptake, and compound 1 further increased insulin-stimulated glucose uptake on C2C12 myotubes, in a dose-dependent manner (Figure 3B). At the concentration of $40 \mu \mathrm{M}$, compound 1 increased insulin-stimulated glucose uptake by $56.0 \%$, compared with the insulin-treated cells. Upon insulin stimulation, its receptor is autophosphorylated on tyrosine residues, which in turn phosphorylates and recruits IRS1 (Tyr 632). Tyrosine phosphorylated IRS1 further activates the phosphatidylinositol 3-kinase (PI3K) and protein kinase B (Akt, Ser 473), leading to cell membrane translocation of glucose transporter type 4 (GLUT4) to uptake glucose [20]. Thus, the key regulators of insulin signaling pathway in compound 1-treated C2C12 myotubes were evaluated by using Western blots. Compound 1 treatment $(20 \mu \mathrm{M})$ increased insulin-stimulated phosphorylation of IRS1 and Akt, when compared with those of insulin-treated cells (Figure 3C). Thus, compound 1 improved insulin sensitivity on C2C12 myotubes.

A

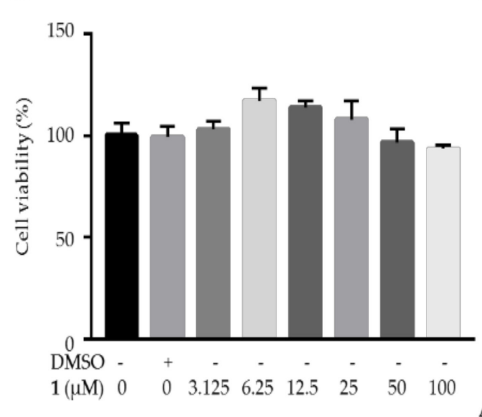

B

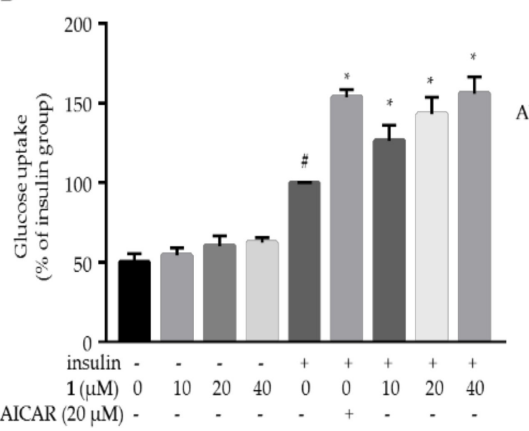

C

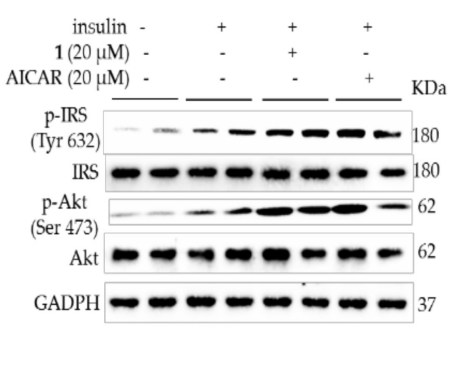

Figure 3. Compound 1 enhanced insulin-stimulated glucose uptake on $\mathrm{C} 2 \mathrm{C} 12$ myotubes through activating insulin signaling pathway. (A) Cytotoxicity of compound $\mathbf{1}$ on C2C12 myotubes when treated for $24 \mathrm{~h}$ by MTT assay. (B) Compound 1 increased insulin-stimulated glucose uptake on C2C12 myotubes. AICAR was used as a positive control. (C) Compound $\mathbf{1}$ activated the insulin signaling pathway in C2C12 myotubes. The expressions of $p$-IRS-1, IRS-1, $p$-Akt, Akt, and GAPDH were analyzed by Western blots. "+" means presence, and "-" means absence. Data are expressed as mean $\pm \mathrm{SD}, n=$ 6. \# $p<0.0001$, control vs. insulin; * $p<0.001$, compound 1 or AICAR vs. insulin.

\section{Materials and Methods}

\subsection{General Experimental Procedures}

Optical rotation data were recorded on an Autopol VI polarimeter (Rudolph Research Analytical, Hackettstown, NJ, USA). UV absorption was monitored with a Varian CARY 50 spectrophotometer (Agilent Technologies, Clara, CA USA). IR spectra were obtained on a PerkinElmer spectrum-100 FTIR spectrometer (PerkinElmer, Waltham, MA, USA) using KBr disks. Electronic circular dichroism (ECD) spectra were measured on a Jasco J-180 spectrophotometer (Jasco, Tokyo, Japan). NMR spectra were recorded on a Bruker Avance-600 NMR spectrometer (Bruker, Fällanden, Switzerland). The chemical shift $\delta$ values were presented in ppm, and the coupling constants $(J)$ were given in Hz. HRESIMS spectra were recorded on an LTQ-Orbitrap XL spectrometer (ThermoFisher Scientific, Bremen, Germany). Silica gel (300-400 mesh, Qingdao Haiyang Chemical Co., Ltd., Qingdao, China) and MCI gel (CHP20P, 75-150 $\mu \mathrm{m}$, Mitsubishi Chemical Industries Ltd., Tokyo, Japan) were used for column chromatography (CC). All solvents were analytical grade (TianJing Chemical Plant, Tianjing, China). Precoated silica gel 
GF254 plates (Qingdao Haiyang Chemical Co., Ltd.) were used for TLC. TLC spots were viewed at $254 \mathrm{~nm}$ and visualized by spraying with $5 \% \mathrm{H}_{2} \mathrm{SO}_{4}$ in EtOH. Preparative HPLC was performed on a Shimadzu LC-20AP instrument (Shimadzu, Kyoto, Japan) with a SPD-M20A PDA detector (Shimadzu, Kyoto, Japan), using a C18 column $\left(19 \times 250 \mathrm{~mm}, 5 \mu \mathrm{m}\right.$, Waters, SunFire ${ }^{\mathrm{TM}}$, Milford, MA, USA) and a gradient solvent system comprised of $\mathrm{H}_{2} \mathrm{O}$ and $\mathrm{CH}_{3} \mathrm{CN}$ at a flow rate of $10 \mathrm{~mL} / \mathrm{min}$.

\subsection{Plant Material}

The seeds of C. minax were collected from Zhaoping County, Guangxi Zhuang Autonomous Region, People's Republic of China, in October 2018, and identified by Professor Changqiang Ke from Shanghai Institute of Materia Medica, Chinese Academy of Sciences (Shanghai, China). A voucher was deposited at the herbarium of the Institute of Chinese Medical Sciences, University of Macau (No. 20181003).

\subsection{Extraction, Isolation and Characterization of Compounds}

The air-dried seeds of C. minax (15 kg) were ground and extracted with 95\% ethanol ( $45 \mathrm{~L} \times 3$ times, each 7 days). The pooled extracts were concentrated under reduced pressure to yield a residue $(1.58 \mathrm{~kg})$, which was then suspended in hot water $(5 \mathrm{~L})$ and extracted with petroleum ether $(\mathrm{PE}, 3 \mathrm{~L} \times$ 3 times), chloroform (3 L $\times 3$ times), and EtOAc ( $3 \mathrm{~L} \times 3$ times), successively, yielding a PE ( $586 \mathrm{~g})$, a chloroform ( $86 \mathrm{~g}$ ) and an EtOAc (15 g) fraction. The chloroform fraction ( $85 \mathrm{~g}$ ) was separated by CC over silica gel eluted with PE/acetone (20:1, 15:1, 7:1, 4:1, 3:1, 2:1, and 1:1, v/v), giving 10 fractions (A-J). Fraction C (3.9 g) was subjected to an MCI gel column eluted with $\mathrm{CH}_{3} \mathrm{OH} / \mathrm{H}_{2} \mathrm{O}(0: 1$ to $0: 1)$ to obtain five subfractions ( $\mathrm{C} 1$ to $\mathrm{C} 5)$. Fraction $\mathrm{C} 4(450 \mathrm{mg}$ ) was purified by preparative HPLC, eluting with $\mathrm{CH}_{3} \mathrm{CN} / \mathrm{H}_{2} \mathrm{O}(80-83 \%, v / v)$, to obtain compound 1 (3.7 mg, Supplementary Materials Figure S11). Fraction D (1.9 g) was subjected to CC over MCI gel, eluted with $\mathrm{CH}_{3} \mathrm{OH} / \mathrm{H}_{2} \mathrm{O}(0: 1$ to1:0), to yield ten subfractions (D1 to D10). Fraction D8 (128 mg) was separated by preparative HPLC, eluting with $\mathrm{CH}_{3} \mathrm{CN} / \mathrm{H}_{2} \mathrm{O}(80-100 \%, v / v)$, to obtain compound 2 (7.8 mg, Supplementary Materials Figure S21).

\subsection{1. $\alpha$-Hydroxy-7-oxo-pimara-8(9),15-diene (1)}

White amorphous powder; $[\alpha]^{25} \mathrm{D}+1.2\left(c 0.37, \mathrm{CH}_{3} \mathrm{OH}\right) ; \mathrm{UV}\left(\mathrm{CH}_{3} \mathrm{OH}\right) \lambda_{\max }(\log \varepsilon) 200.0(0.54)$, $245.0(0.54) \mathrm{nm} ; \mathrm{ECD}\left(\mathrm{CH}_{3} \mathrm{OH}, \mathrm{nm}\right) \lambda_{\max }(\Delta \varepsilon) 204.0(+2.2), 250.5(-5.7), 322.0(+1.2) ; \mathrm{IR} v_{\max }(\mathrm{KBr})$ 3452 (strong, broad), 2918, 2854, 1742, 1682, 1393, 1203, 1134, $1023 \mathrm{~cm}^{-1},{ }^{1} \mathrm{H}$ - and ${ }^{13} \mathrm{C}-\mathrm{NMR}$ data (see Table 1); HRESIMS $m / z 303.2326[\mathrm{M}+\mathrm{H}]^{+}$(calcd for $\mathrm{C}_{20} \mathrm{H}_{31} \mathrm{O}_{2}, 303.2324$ ).

\subsubsection{9-Hydroxy-2 $\alpha$-acetoxy-7-oxo-pimara-8(9),15-diene (2)}

White amorphous powder; $[\alpha]^{25} \mathrm{D}-4.4\left(c 0.78, \mathrm{CH}_{3} \mathrm{OH}\right) ; \mathrm{UV}\left(\mathrm{CH}_{3} \mathrm{OH}\right) \lambda_{\max }(\log \varepsilon) 194.9(0.53)$, $250.1(0.40) \mathrm{nm} ; \mathrm{ECD}\left(\mathrm{CH}_{3} \mathrm{OH}, \mathrm{nm}\right) \lambda_{\max }(\Delta \varepsilon) 220.0(+4.7), 253.5(-5.9), 327.0(+1.5) ; \mathrm{IR} v_{\max }(\mathrm{KBr}) 3442$ (strong, broad), 2930, 2871, 1729, 1658, 1378, 1243, $1030 \mathrm{~cm}^{-1} ;{ }^{1} \mathrm{H}$ - and ${ }^{13} \mathrm{C}-\mathrm{NMR}$ data (see Table 1); HRESIMS $m / z 361.2374[\mathrm{M}+\mathrm{H}]^{+}$(calcd for $\mathrm{C}_{22} \mathrm{H}_{33} \mathrm{O}_{4}, 361.2379$ ).

\subsection{PTP1B Assay}

PTP1B enzymatic reaction was performed as described previously $[15,21]$. The PTP1B enzymatic activity was measured in $100 \mu \mathrm{L}$ reaction buffer [1 mM bovine serum albumin (BSA), $50 \mathrm{mM}$ 3-( $\mathrm{N}$ morpholino)-propanesulfonic acid, $1 \mathrm{mM}$ dithiothreitol, and $1 \mathrm{mM}$ ethylenediaminetetraacetic acid (EDTA), pH 6.5] containing $15 \mathrm{nM}$ human recombinant PTP1B enzyme (Sigma-Aldrich, St Louis, MO USA) and $10 \mathrm{mM}$ pNPP (Sigma-Aldrich, St Louis, MO, USA), in 96-well plates. Different concentrations of compound 1 and oleanolic acid were added in the designated wells, and the plate was pre-incubated at $37^{\circ} \mathrm{C}$ for $30 \mathrm{~min}$. Subsequently, pNPP was added to each well, and the plate was incubated at $37^{\circ} \mathrm{C}$ for $45 \mathrm{~min} .50 \mu \mathrm{L} \mathrm{NaOH}(3 \mathrm{M})$ was added to each well to stop reaction. pNPP was dephosphorylated to yield the product $p$-nitrophenol, which could be monitored at an absorbance of $405 \mathrm{~nm}$ with a SpectraMax M5 microplate reader (Molecular Devices, San Jose, CA, USA), and the slope of the initial rate of the kinetic 
curve in each well was applied to determine the activity of PTP1B. The wells with only DMSO and pNPP were considered as blank control; the wells with DMSO, pNPP and enzyme were considered as negative control. The PTP1B inhibitory ratio was calculated as: $\left(A_{\text {negative }}-A_{\text {sample }}\right) /\left(A_{\text {negative }}-A_{\text {blank }}\right) \times 100 \%$. $A_{\text {negative, }} A_{\text {sample }}$ and $A_{\text {blank }}$ were absorbance for negative control, sample and blank control, respectively. The $\mathrm{IC}_{50}$ value was calculated with Graphpad Prism 6.0 software (GraphPad, San Diego, CA, USA). The PTP1B enzyme kinetic assay was performed as described above. The absorbance was recorded every $5 \mathrm{~min}$ for a half hour. The Dixon plot experiment was performed with various concentrations of $p$-NPP, and the Lineweaver-Burk plot experiment was performed with various concentrations of compound 1. The Ki value was obtained from the interpretation of Dixon plots.

\subsection{Cell Culture}

C2C12 myoblasts were obtained from American Type Culture Collection (Manassas, VA, USA) and maintained in Dulbecco's modified Eagle medium (DMEM, Thermo Fisher, Waltham, MA, USA) with 10\% fetal bovine serum (FBS, Thermo Fisher, Waltham, MA, USA) and 1\% penicillin-streptomycin $(\mathrm{P} / \mathrm{S})$, in a $5 \% \mathrm{CO}_{2}$ incubator at $37^{\circ} \mathrm{C}$. When reach $70-80 \%$ confluence, cells were incubated with fresh medium containing $2 \%$ heat-inactivated horse serum (HS, Thermo Fisher, Waltham, MA, USA) and 1\% $\mathrm{P} / \mathrm{S}$ for 4 days, to differentiate into myobutes. Media were changed every day.

\subsection{Cell Viability}

MTT assay was performed to determine cell viability as described previously [18,19]. The fully differentiated C2C12 myotubes were treated with different concentrations of compounds for $24 \mathrm{~h}$. DMSO was used as a blank control. Then cells were incubated with DMEM containing $1 \mathrm{mg} / \mathrm{mL} \mathrm{MTT} \mathrm{for}$ additional 4 h. $100 \mu \mathrm{L}$ DMSO was added to each well to dissolve the formazan crystals. The absorbance at $570 \mathrm{~nm}$ was recorded by a SpectraMax M5 microplate reader. The cell viability was calculated as following: $(\mathrm{As}-\mathrm{A} 0) /(\mathrm{Ac}-\mathrm{A} 0) \times 100 \%$, where As, Ac and A0 were the absorptions of test sample, negative control (DMSO) and blank control, respectively.

\subsection{Insulin Stimulated Glucose Uptake}

Glucose uptake was performed as described previously [22]. In brief, C2C12 myotubes were treated with different concentrations of compound 1 for $24 \mathrm{~h}$. After washed with Krebs-Ringer's phosphate (KRP) buffer (137 mM NaCl, $20 \mathrm{mM}$ HEPES, $4.7 \mathrm{mM} \mathrm{KCl}, 1.2 \mathrm{mM} \mathrm{KH}_{2} \mathrm{PO}_{4}, 1.2 \mathrm{mM} \mathrm{MgSO}_{4}$, $2 \mathrm{mM}$ pyruvate and $2.5 \mathrm{mM} \mathrm{CaCl}_{2}, \mathrm{pH}$ 7.4) twice, the cells were incubated for $3 \mathrm{~h}$ in KRP buffer containing $0.2 \%$ BSA. Subsequently, the cells were stimulated insulin $(0.1 \mu \mathrm{M}$ in KRP buffer) for $30 \mathrm{~min}$. After washed with KRP buffer once, the cells were incubated in 2-NBDG solution [2-(N-(7-nitrobenz2-oxa-1, 3-diazol-4-yl) amino)-2-deoxyglucose (Sigma-Aldrich, St Louis, MO, USA), $100 \mu \mathrm{M}$ in KRP buffer] for $30 \mathrm{~min}$. The intracellular content of 2-NBDG was recorded by a fluorescence spectrometer (excitation wavelength: 475 nm; emission wavelength: $550 \mathrm{~nm}$, Molecular Devices, San Jose, CA, USA). The fluorescence intensity was further normalized by protein content.

\subsection{Western Blot Analysis}

Western blot analysis was performed as described previously [23,24]. In brief, protein concentration of sample was determined by using the BCA (bicinchoninic acid) protein assay kit (Thermo Fisher, Waltham, MA, USA). The same amount of proteins $(30 \mu \mathrm{g})$ were separated by SDS-PAGE (sodium dodecyl sulfate-polyacrylamide gel electrophoresis) and transferred to polyvinylidene fluoride (PVDF) membranes (Bio-Rad, Hercules, CA, USA). Then, the membrane was blocked in TBST buffer (100 mM $\mathrm{NaCl}, 10 \mathrm{mM}$ Tris-HCl, pH 7.5 and $0.1 \%$ Tween-20) with 5\% nonfat milk for $1 \mathrm{~h}$ at room temperature. After washed with TBST twice, the membrane was incubated with specific primary antibodies overnight at $4{ }^{\circ} \mathrm{C}$. After washing with TBST three times, the membrane was incubated in TBST containing a horseradish peroxidase-conjugated secondary antibody for $2 \mathrm{~h}$ at room temperature. The immuneblotting signals were developed using a SuperSignal West Femto Maximum Sensitivity Substrate 
kit (Thermo Fisher, Waltham, MA, USA) and visualized using the ChemiDoc MP Imaging System. Antibodies against $p$-Akt (Ser 473, cat. no. sc-7985), Akt (cat. no. sc-8312), p-IRS-1 (Tyr 632, cat. no. sc-17196), IRS-1 (cat. no. sc-8038), and GAPDH (cat. no. sc-25778) were purchased from Santa Cruz Biotechnology (Santa Cruz, CA, USA).

\subsection{Statistical Analysis}

All data were expressed as mean \pm SD (standard deviation) based on at least three independent experiments and analyzed by Graphpad Prism 6 (GraphPad Software, San Diego, CA, USA, https: //www.graphpad.com/scientific-software/prism/). One-way ANOVA (analysis of variance) was used for statistical comparison, and $P$-values less than 0.05 were considered statistically significant.

\section{Conclusions}

In summary, the isolation and structure elucidation of two pimarane diterpenoids from C. minax, 2 $\alpha$-hydroxy-7-oxo-pimara-8(9),15-diene (1) and 19-hydroxy-2 $\alpha$-acetoxy-7-oxo-pimara-8(9),15-diene (2), were described in the current study, as well as their PTP1B inhibitory and insulin-sensitizing effects. 2 $\alpha$-Hydroxy-7-oxo-pimara-8(9),15-diene(1) potentially inhibits PTP1B enzyme with an $\mathrm{IC}_{50}$ value of $13.69 \pm 2.72 \mu \mathrm{M}$. The enzyme kinetic study indicated that 1 is a competitive inhibitor of PTP1B with a $\mathrm{Ki}$ value of $13.69 \pm 2.72 \mu \mathrm{M}$. In addition, compound 1 possesses a 2-NBDG uptake enhancing property in insulin-stimulated $\mathrm{C} 2 \mathrm{C} 12$ myotubes. The results suggest that pimarane diterpenoids from $\mathrm{C}$. minax may be the potential natural products for the development of insulin sensitizers.

Supplementary Materials: The following are available online. NMR, IR HRESIMS, ECD and UV spectroscopic data of isolated compounds (1 and 2 ).

Author Contributions: Conceptualization, C.P. and L.L.; Methodology, Y.X., Z.F. and D.L.; Writing-Original Draft Preparation, D.L. and L.L.; Writing-Review \& Editing, T.Z., P.L., J.C., D.L. and C.P.; Project Administration, L.L.; Funding Acquisition, L.L. All authors have read and agreed to the published version of the manuscript.

Funding: Financial support by Science and Technology Development Fund, Macao S.A.R (FDCT 0031/2019/A1), the Research Fund of University of Macau (MYRG2017-00109-ICMS and MYRG2018-00037-ICMS), the Open Research Fund of Chengdu University of Traditional Chinese Medicine Key Laboratory of Systematic Research of Distinctive Chinese Medicine Resources in Southwest China (2020GZ2011011), National Natural Science Foundation of China (81872754 and 82073715), and Key-Area Research and Development Program of Guangdong Province, China (2020B1111110003) are gratefully acknowledged. The APC was funded by the Open Research Fund of Chengdu University of Traditional Chinese Medicine Key Laboratory of Systematic Research of Distinctive Chinese Medicine Resources in Southwest China (2020GZ2011011).

Conflicts of Interest: The authors declare no conflict of interest.

\section{References}

1. Yu, Z.H.; Zhang, Z.Y. Regulatory mechanisms and novel therapeutic targeting strategies for protein tyrosine phosphatases. Chem. Rev. 2018, 118, 1069-1091. [CrossRef] [PubMed]

2. Maheshwari, N.; Karthikeyan, C.; Trivedi, P.; Moorthy, N. Recent advances in protein tyrosine phosphatase 1B targeted drug discovery for type II diabetes and obesity. Curr. Drug Targets 2018, 19, 551-575. [CrossRef] [PubMed]

3. Zhang, Z.Y.; Lee, S.Y. PTP1B inhibitors as potential therapeutics in the treatment of type 2 diabetes and obesity. Expert Opin. Investig. Drugs 2003, 12, 223-233. [CrossRef] [PubMed]

4. Lantz, K.A.; Hart, S.G.; Planey, S.L.; Roitman, M.F.; Ruiz-White, I.A.; Wolfe, H.R.; McLane, M.P. Inhibition of PTP1B by trodusquemine (MSI-1436) causes fat-specific weight loss in diet-induced obese mice. Obesity 2010, 18, 1516-1523. [CrossRef] [PubMed]

5. Jiang, C.S.; Liang, L.F.; Guo, Y.W. Natural products possessing protein tyrosine phosphatase 1B (PTP1B) inhibitory activity found in the last decades. Acta Pharmacol. Sin. 2012, 33, 1217-1245. [CrossRef]

6. Zhao, B.T.; Nguyen, D.H.; Le, D.D.; Choi, J.S.; Min, B.S.; Woo, M.H. Protein tyrosine phosphatase 1B inhibitors from natural sources. Arch. Pharmacal Res. 2018, 41, 130-161. [CrossRef]

7. Nanjing University of Traditional Chinese Medicine. Dictionary of Chinese Traditional Medicine; Shanghai People's Publishing House: Shanghai, China, 2005; Volune 1, p. 3913. 
8. Bao, H.; Zhang, L.L.; Liu, Q.Y.; Feng, L.; Ye, Y.; Lu, J.J.; Lin, L.G. Cytotoxic and pro-apoptotic effects of cassane diterpenoids from the seeds of Caesalpina sappan in cancer cells. Molecules 2016, 21, 791. [CrossRef]

9. Zanin, J.L.B.; De Carvalho, B.A.; Martineli, P.S.; Dos Santos, M.H.; Lago, J.H.G.; Sartorelli, P.; Viegas, C., Jr.; Soares, M.G. Of the genus Caesalpinia L. (Caesalpiniaceae): Phytochemical and pharmacological characteristics. Molecules 2012, 17, 7887-7902. [CrossRef]

10. Yodsaoue, O.; Karalai, C.; Ponglimanont, C.; Tewtrakul, S.; Chantrapromma, S. Pulcherrins D-R, potential anti-inflammatory diterpenoids from the roots of Caesalpinia pulcherrima. Tetrahedron 2011, 67, 6838-6846. [CrossRef]

11. Xiao, F.; Tang, C.P.; Ke, C.Q.; Yao, S.; Ye, Y. Rearranged diterpenoids from the seeds of Caesalpinia sappan. Chin. Chem. Lett. 2016, 27, 1751-1754. [CrossRef]

12. Pinto, A.C.; Silva, A.J.R.; Mayer, L.M.U.; Braz, R.F. Compactone, a new diterpenoid from Vellozia compacta. Phytochem. Lett. 1979, 18, 2036-2037. [CrossRef]

13. Touche, E.M.G.; Lopez, E.G.; Reyes, A.; Sanchez, H.; Honecker, F.; Achenbach, H. Parryin, a diterpene with a tricyclic 6-7-5-ring system from Salvia parryi. Phytochemistry 1997, 45, 387-390. [CrossRef]

14. Nogueira, M.S.; Da Costa, F.B.; Brun, R.; Kaiser, M.; Schmidt, T.J. Ent-Pimarane and ent-kaurane diterpenes from Aldama discolor (Asteraceae) and their antiprotozoal activity. Molecules 2016, 21, 1237. [CrossRef] [PubMed]

15. Zhou, J.; Zuo, Z.; Liu, J.; Zhang, H.; Zheng, G.; Yao, G. Discovery of highly functionalized 5,6-seco-grayanane diterpenoids as potent competitive PTP1B inhibitors. Org. Chem. Front. 2020, 7, 820-828. [CrossRef]

16. Cornish-Bowden, A.; Eisenthal, R. Statistical considerations in the estimation of enzyme kinetic parameters by the direct linear plot andother methods. Biochem. J. 1974, 139, 721-730. [CrossRef]

17. Dixon, M. The determination of enzyme inhibitor constants. Biochem. J. 1953, 55, 170-171. [CrossRef]

18. Shen, S.; Liao, Q.; Zhang, T.; Pan, R.; Lin, L. Myricanol modulates skeletal muscle-adipose tissue crosstalk to alleviate high-fat diet-induced obesity and insulin resistance. Br. J. Pharmacol. 2019, 176, 3983-4001. [CrossRef]

19. Shen, S.; Liao, Q.; Liu, J.; Pan, R.; Lee, S.M.; Lin, L. Myricanol rescues dexamethasone-induced muscle dysfunction via a sirtuin 1-dependent mechanism. J. Cachexia Sarcopenia Muscle 2019, 10, 429-444. [CrossRef]

20. Taniguchi, C.M.; Emanuelli, B.; Kahn, C.R. Critical nodes in signalling pathways: Insights into insulin action. Nat. Rev. Mol. Cell. Biol. 2006, 7, 85-96. [CrossRef]

21. Nguyen, P.H.; Tuan, H.N.; Hoang, D.T.; Vu, Q.T.; Pham, M.Q.; Tran, M.H.; To, D.C. Glucose uptake stimulatory and PTP1B inhibitory activities of pimarane diterpenes from Orthosiphon stamineus Benth. Biomolecules 2019, 9, 859. [CrossRef]

22. Fang, Z.; Shen, S.; Wang, J.; Wu, Y.; Zhou, C.; Mo, J.; Lin, L.; Gan, L. Triterpenoids from Cyclocarya paliurus that enhance glucose uptake in 3T3-L1 adipocyts. Molecules 2019, 24, 187. [CrossRef] [PubMed]

23. Li, D.; Liu, Q.; Sun, W.; Chen, X.; Wang, Y.; Sun, Y.; Lin, L. 1,3,6,7-Tetrahydroxy-8-prenylxanthone ameliorates inflammatory responses resulting from the paracrine interaction of adipocytes and macrophages. Br. J. Pharmacol. 2018, 175, 1590-1606. [CrossRef] [PubMed]

24. Li, D.; Liu, Q.; Lu, X.; Li, Z.; Wang, C.; Leung, C.; Wang, Y.; Peng, C.; Lin, L. $\alpha$-Mangostin remodels visceral adipose tissue inflammation to ameliorate age-related metabolic disorders in mice. Aging 2019, 11, 11084-11110. [CrossRef] [PubMed]

Sample Availability: Samples of the compounds are available from the authors. 